\title{
Controversies in the treatment of plasma cell myeloma
}

\author{
Daniel E. Bergsagel \\ University of Toronto and Ontario Cancer Institute, Canada.
}

\section{Introduction}

Plasma cell myeloma is a chronic disease of the haemopoietic cell system in which there is uncontrolled proliferation of a clonal population of B-cells. There are many similarities between plasma cell myeloma and other clonal haemopathies such as chronic granulocytic leukaemia.

Although the median survival of patients with plasma cell myeloma has increased from seven months before the general use of alkylating agents for treatment (Osgood, 1960) to about 30 months today, the treatment of this disease is still unsatisfactory and controversial. Useful remissions are achieved with a one to two logarithm reduction in the myeloma cell mass, but from $10^{10}$ to $10^{11}$ myeloma cells remain. Attempts to reduce this residual myeloma cell mass further with more intensive treatment have not been very successful, and there is little evidence that any patient has achieved a complete remission, or been cured of the disease.

Since there is no evidence that treatment benefits asymptomatic patients with benign monoclonal gammopathy, or stable smouldering myeloma, there is general agreement that only patients with progressive, symptomatic disease should be treated.

Of the many controversies about the treatment of plasma cell myeloma, I have chosen to discuss only six in this article. The major controversy has to do with the choice of primary therapy for remission induction. This controversy is followed by a discussion of the role of maintenance therapy, the choice of irradiation or chemotherapy in the treatment of back pain, the use of agents to strengthen the bony skeleton, the choice of second-line therapy, and the reasons for the increased incidence of acute leukaemia in myeloma patients.

\section{Are drug combinations better than melphalan and prednisone as initial therapy?}

For many years the standard treatment for symptomatic myeloma patients has been melphalan and

D.E. Bergsagel, M.D., D.Phil.

Correspondence: The Princess Margaret Hospital, 500 Sherbourne Street, Toronto, Canada M4X 1K9 prednisone. This treatment (MP) results in objective responses in 40 to $50 \%$ of patients, and prolongs the median survival to between 19 and 39 months (Table I).

There have been many attempts to achieve better results by combining drugs with varied mechanisms of action and different limiting toxicities (Table II). One of the best known drug combinations, tested in an uncontrolled pilot study at Memorial Hospital in New York, combines vincristine, carmustine (BCNU), melphalan, cyclophosphamide and prednisone (VBMCP, M-2 protocol). The initial report compared this drug combination with a historical control group treated with MP (Case et al., 1977; Lee et al., 1982; Lee, 1984). Although the authors claim that the M-2 protocol increased the frequency of objective responses and improved survival in comparison to MP, the design and analysis of the study has been criticized (Bergsagel et al., 1979; Bergsagel, 1982; 1983; 1984). With a historical control group it is difficult to be sure that the prognostic factors and the supportive care are comparable for the two treatment groups. This problem raises the suspicion that patients treated with the M-2 protocol fared better because they had more favourable prognostic factors and/or received better supportive care. A comparison of two methods of treatment requires the use of comparable groups of patients. One method of achieving this is to assign patients at random to the treatment being compared.

Eight studies (Tables I \& II) have been reported in which the effectiveness of various drug combinations has been compared with MP in prospective, randomized clinical trials. The results of treatment with MP are summarized in Table I. Table II contains the data for myeloma patients, assigned at random to receive drug combinations, with a statistical comparison of differences between the response rates and the survival of patients treated with the drug combination and the MP control group.

For patients treated with MP, objective responses were observed in 32 to $53 \%$ of patients using the South Western Oncology Group (SWOG) criteria of response (Alexanian et al., 1972) and in 33 to $56 \%$ with the Chronic Leukemia-Myeloma Task Force Criteria (1968). Median survival from the onset of treatment 
ranged from 19 to 39 months. The variability in the response rates and the survival of these eight groups of patients receiving the same drugs illustrates the important effect that the disease has on the results of treatment. It will be noted that there is a marked overlap between the results of treatment with MP and the results reported for drug combinations in Table II.

Objective responses were observed in 39 to $57 \%$ (using the SWOG criteria), and 45 to $74 \%$ (with the Chronic Leukemia-Myeloma criteria) of patients treated with drug combinations. Median survival ranged from 25 to 41 months. The ECOG has conducted a prospective, randomized trial comparing the M-2 drug combination with MP (Oken et al., 1984). They observed a significantly better objective response rate for the drug combination, but to date no difference in the survival of the two groups has been detected. The Grupo Argentino de Tratamiento de la Leucemia Aguda (GATLA) investigated a similar drug combination, in which semustine (methyl CCNU) was substituted for BCNU, but observed no significant difference in response rate or survival in comparison with the MP group (Pavlovsky et al., 1984).

A recent SWOG study allocated 239 myeloma patients at random to one of three treatments: (1) VMCP alternating with VCAP; (2) VMCP for three
Table I Response and survival of previously untreated myeloma patients to melphalan and prednisone*

\begin{tabular}{lccc}
\hline $\begin{array}{l}\text { Study group: } \\
\text { Reference }\end{array}$ & $\begin{array}{c}\text { Number } \\
\text { of } \\
\text { patients }\end{array}$ & $\begin{array}{c}\text { Response** } \\
\text { \% evaluable }\end{array}$ & $\begin{array}{c}\text { Median } \\
\text { survival } \\
\text { (months) }\end{array}$ \\
\hline $\begin{array}{l}\text { ECOG, Abramson } \\
\text { et al., 1982 }\end{array}$ & 92 & 43 (B) & 19 \\
$\begin{array}{l}\text { SWOG, Salmon } \\
\text { et al., 1983 }\end{array}$ & 79 & $32(\mathrm{~A})$ & 24 \\
$\begin{array}{l}\text { CALGB, Harley } \\
\text { et al., 1979 }\end{array}$ & 126 & $56(\mathrm{~B})$ & 25 \\
$\begin{array}{l}\text { NCI-C, Bergsagel } \\
\text { et al., 1979 }\end{array}$ & 125 & $40(\mathrm{~A})$ & 28 \\
$\begin{array}{l}\text { ECOG, Oken } \\
\quad \text { et al., 1984 }\end{array}$ & 131 & 53 (B) & 29 \\
$\begin{array}{l}\text { GATLA, Cavagnaro } \\
\text { et al., 1980 }\end{array}$ & 72 & 33 (B) & 32 \\
$\begin{array}{l}\text { Alexanian } \\
\text { et al., 1984 }\end{array}$ & 30 & $53(\mathrm{~A})$ & 37 \\
$\begin{array}{l}\text { GATLA, Pavlovsky } \\
\text { et al., 1984 }\end{array}$ & 110 & 35 (B) & 39 \\
\hline
\end{tabular}

* these melphalan and prednisone-treated patients were compared to a randomized group treated with a drug combination shown in Table II.

*** response defined by: (A) SWOG criteria ( $\geqq 75 \%$ reduction in M-protein synthesis. Alexanian et al.. 1972); or (B) Chronic Leukaemia-Myeloma Task Force Criteria, 1968 (>50\% decrease in M-protein).

Table II Randomized studies of drug combinations versus oral melphalan and prednisone for plasma cell myeloma*

\begin{tabular}{|c|c|c|c|c|c|c|}
\hline \multirow[t]{2}{*}{$\begin{array}{l}\text { Study group; } \\
\text { Reference }\end{array}$} & \multirow[t]{2}{*}{$\begin{array}{c}\text { Drug** } \\
\text { combination }\end{array}$} & \multirow[t]{2}{*}{$\begin{array}{l}\text { Number } \\
\text { of patients }\end{array}$} & \multirow[t]{2}{*}{$\begin{array}{l}\text { Response*** } \\
\% \text { evaluable }\end{array}$} & \multirow[t]{2}{*}{$\begin{array}{c}\text { Median } \\
\text { survival (Mo.) }\end{array}$} & \multicolumn{2}{|c|}{$\begin{array}{l}\text { Probability that } \\
\text { drug combination } \\
\text { better than } M P\end{array}$} \\
\hline & & & & & Response & Survival \\
\hline $\begin{array}{l}\text { ECOG, Abramson } \\
\quad \text { et al., } 1982\end{array}$ & BCP & 96 & 50 (B) & 25 & NS & NS \\
\hline SWOG, Salmon & VMCP, VCAP & 160 (all) & 53 (A) & 40 & 0.002 & 0.01 \\
\hline et al., 1983 & & 82 IIIA & 45 (A) & not stated & not stated & 0.001 \\
\hline CALGB, Harley & MCBP & 124 (all) & 68 (B) & not stated & 0.047 & NS \\
\hline et al., 1979 & (all i.v.) & $53($ III) & 64 (B) & 23 & NS & 0.02 \\
\hline $\begin{array}{l}\text { NCI-C, Bergsagel } \\
\text { et al., } 1979\end{array}$ & $\begin{array}{l}\text { MCBP } \\
\text { (M-oral) }\end{array}$ & 174 & 39 (A) & 31 & NS & NS \\
\hline $\begin{array}{l}\text { ECOG, Oken } \\
\text { et al., } 1984\end{array}$ & VBMCP (M2) & 134 & 74 (B) & 33 & $<0.001$ & NS† \\
\hline $\begin{array}{l}\text { GATLA, Cavagnaro } \\
\text { et al., } 1980\end{array}$ & $\mathrm{CMeCP}$ & 67 & 48 (B) & 32 & NS & NS \\
\hline $\begin{array}{l}\text { Alexanian } \\
\text { et al., } 1984\end{array}$ & $\begin{array}{l}\text { VMCP, VCAP } \\
\text { and VBAP }\end{array}$ & 76 & $57(A)$ & 26 & NS & NS \\
\hline $\begin{array}{l}\text { GATLA, Pavlovsky } \\
\text { et al., } 1984\end{array}$ & $\begin{array}{l}\text { VMe CMCP } \\
\text { and VBAP }\end{array}$ & 92 & 45 (B) & 41 & NS & NS \\
\hline
\end{tabular}

* the results for control groups treated with melphalan and prednisone are shown in Table $I$.

** V, vincristine; M, melphalan; C, cyclophosphamide; A, adriamycin (doxorubicin); B, BCNU (carmustine); MeC, methyl CCNU (semustine); $P$, prednisone

*** response defined by: A. SWOG criteria ( $\geqq 75 \%$ reduction in M-protein synthesis, Alexanian et al., 1972); or B. Chronic Leukaemia-Myeloma Task Force criteria, 1968 (>50\% decrease in M-protein)

$\uparrow$ Not significant 
cycles alternating with VBAP for three cycles; and (3) MP. The doses of these drugs were adjusted so that they could be repeated at three-week intervals (Salmon et al., 1983). An additional 106 myeloma patients were randomized in this study and treated at the University of Texas, M.D. Anderson Hospital; the results for these patients were reported separately (Alexanian \& Dreicer, 1984). The results for the main SWOG group differ from those at the M.D. Anderson Hospital. The SWOG found that the response rate for patients treated with the drug combination $(53 \%)$ was significantly better than for MP $(32 \%, P=0.002)$, while at the M.D. Anderson Hospital the drug combination response rate $(57 \%)$ was not significantly different from the response rate for MP $(53 \%)$. In the SWOG report the survival of myeloma patients treated with the drug combinations (median $\mathbf{4 0}$ months) was significantly longer than for MP (median 24 months, $P=0.01$ ), while at the M.D. Anderson Hospital the survival of drug combination patients (median 26 months) was not significantly different than for those treated with MP (median 37 months). It is unfortunate that the results of this important trial were not analysed and reported as a single study. The results for one-third of the patients randomized in this study and treated at the M.D. Anderson Hospital are sufficiently different from the results of the remaining patients reported by the SWOG, that one wonders if significant differences between patients treated with drug combinations and MP would be observed if the two reports were combined.

The major benefit of combination chemotherapy in the SWOG study was observed in patients with Stage IIIA disease; the survival of Stage I and II patients in the two treatment groups was not significantly different. Although this study was carefully analysed, doubts have been expressed about the conclusion that Stage IIIA patients should be treated aggressively with combination chemotherapy (Bergsagel, 1983). There are four main reasons for these doubts.

There is little evidence that repeating melphalan $\left(8 \mathrm{mg} / \mathrm{m}^{2} / \mathrm{d} \times 4\right)$ and prednosone every three weeks is an optimal dosage schedule. A total melphalan dose of $32 \mathrm{mg} / \mathrm{m}^{2}$ causes a slow fall in leukocyte and platelet counts, reaching a nadir at about three weeks, with recovery by four to six weeks. Repeating melphalan at three-week intervals would be expected to lead to cumulative toxicity and subsequent missed or reduced doses. In recent reports of the effectiveness of MP in the treatment of myeloma (Table I), median survival times have ranged from 19 to 39 months. The median survival time of 24 months in the SWOG study is in the lower range, since six other groups report longer median survival times. Thus, the patients treated with MP in the SWOG study may have been either a poor prognosis group, or the dosage schedule for MP was less effective than that used in other studies.
The median duration of the remissions achieved with combination chemotherapy and MP were similar in the SWOG study. The duration of a chemotherapyinduced remission provides a reasonable estimate of the tumour cell-kill. If alternating combination chemotherapy improves the survival of myeloma patients by achieving a greater decrease in the myeloma cell mass than MP, one would expect to observe significantly longer remissions in patients treated with drug combinations. The fact that the median remission durations were about 30 months for both groups is surprising and suggests that the improved survival of patients treated with drug combinations did not result from enhanced destruction of myeloma cells by the drug combination.

The fact that the survival curve for patients treated with alternating combination chemotherapy is approaching the survival curve for MP patients in the SWOG study is also worrisome because this suggests that the proportion of long-term survivors will be similar in the two groups. If combination chemotherapy were more effective than MP in destroying myeloma cells, one would expect to observe an increase in the proportion of long-term survivors treated by this method.

Finally, it should be noted that the improved results reported for combination chemotherapy by the SWOG are almost unique, and need to be confirmed. Among the eight randomized studies listed in Table II, only the SWOG study observed a significant improvement in the response rate and survival of all myeloma patients treated with combination chemotherapy. The CALGB study of Harley et al. (1979), partially supports the view that combination chemotherapy is better than MP. This group found that Stage III patients treated with intravenous doses of MCB and oral prednisone lived significantly longer than similar patients treated with oral MP. The design of this study was flawed by the fact that melphalan was given intravenously to the drug combination group and orally to the MP group. It is difficult to compare treatment groups since the absorption of melphalan from the gastrointestinal tract is variable, and the effective melphalan dose received by patients in the two groups was different. When melphalan was administered orally to both the MCBP and the MP groups, no improvement in response rates or survival was observed for MCBP for either the total group, or the Stage III subgroup (Bergsagel et al., 1979). CALGB compared intravenous melphalan with intravenous MCB and MCBA in a later study (Cooper et al., 1983) and found that it was just as effective as the drug combinations in producing objective responses and prolonging survival. Thus, the addition of cyclophosphamide, BNCN and adriamycin did not improve the results of treatment as compared to intravenous melphalan. 
It wil be clear from this review that I do not think that combination chemotherapy has been shown to be more effective than MP for any stage of myeloma. In the study reported by Alexanian \& Dreicer (1984), the unexpectedly long median survival of myeloma patients randomized to treatment with MP (37 months), as compared to those treated with drug combinations (26 months) was partially attributed to the inclusion of more patients with favourable prognostic factors in the MP group. This observation illustrates the fact that the survival of groups of myeloma patients is influenced more strongly by the prognostic factors of the disease than by the treatment, and this probably explains the occasional trial in which drug combinations appear to be superior to MP. Since potentially lethal doses of chemotherapy and radiation failed to eliminate the myeloma cell population from a patient receiving a marrow transplant from an identical twin (Osserman et al., 1982), I think that the chances of curing myeloma patients with currently available agents are small. We need to learn more about the biology of myeloma and discover new agents with greater specificity before we can expect to rise above the current therapeutic plateau.

\section{The treatment of back pain}

Back pain is a common symptom in myeloma patients. Two types of bone resorption give rise to this symptom. The commonest is a localized, purely osteolytic, 'punched out' lesion, with no evidence of osteoblastic bone repair at the margins. In other patients there is more generalized osteoporosis, without definite lytic lesions.

The effects of generalized osteoporosis are usually seen best in the spine. The vertebrae lose much of their density, and compression collapse of the vertebrae leads to the development of the 'fish mouth' deformity. With extensive demineralization, most patients complain of spasms of back pain, initiated by movement, and probably caused by microfractures of the weakened bone structure.

Osteolytic vertebral lesions may be discovered by finding that a pedicle is missing (the 'winking owl' sign, Livingston \& Perrin, 1978). Lytic lesions may involve the vertebral bodies in others. These lytic lesions contain large collections of myeloma cells, which may extend beyond the vertebral body and form paraspinal plasmacytomas. It is important to look for paraspinal masses in myeloma patients because the plasmacytomas may invade a vertebral foramen and cause extradural cord compression.

There are two treatment choices: irradiation or chemotherapy. Both forms of treatment are effective for certain indications, but for many the choice is arbitrary and is determined largely by the available facilities and the training of a physician. The following principles have been developed after treating the back pain of myeloma patients in association with radiation oncologists. These principles may be controversial, because they have not been tested in clinical trials, but they have proven to be useful for me. The principles are as follows:

\section{Irradiation}

Radiate lytic lesions, and lesions associated with paraspinal masses. Radiation usually results in a prompt shrinkage of the plasma cell infiltrate and improvement in the pain. At the Princess Margaret Hospital we have found that relatively low doses (e.g. $2000 \mathrm{cGY}$ in 5 fractions) are adequate in the treatment of localized lesions. Rather large fields, such as the lower half of the body ( $800 \mathrm{cGy}$ in one dose) may be required to control the pain of patients with advanced disease who have extensive lytic lesions in the lower vertebra, pelvis and femora. Treatment with melphalan and prednisone, directed at controlling systemic manifestations of the disease, should be started as soon as possible. We usually give this chemotherapy together with the radiotherapy.

\section{Chemotherapy}

Use chemotherapy when there is extensive osteoporosis, and no localized lytic lesions. In these patients all of the vertebrae are osteoporotic and there may be one, or more, compression fractures. In my experience radiating the compressed vertebrae, or the entire spinal column, usually does not relieve the back pain. If the whole vertebral column is irradiated, the resulting marrow suppression will often delay the use of chemotherapy. A. course of melphalan and prednisone, however, will usually improve the back pain, even if an objective response, with a $50 \%$ decrease in the M-protein concentration, is not achieved.

\section{Strengthening the skeleton of myeloma patients}

The bony lesions described above are a major problem in the management of patients with myeloma. In patients who are responding to treatment with melphalan and prednisone, with a decrease in the serum and urinary $\mathbf{M}$-protein, a rise in haemoglobin and improvement in bone pain, it is not unuscial to observe progressive demineralization and other evidence of deterioration of the bony skeleton. Many patients lose 10 to $20 \mathrm{~cm}$ in height as osteoporotic vertebra collapse. One interesting patient who had lost $12 \mathrm{~cm}$ in height, expressed the fear that her rib cage would soon be supported by her hip bones.

Treatment with fluorides, calcium and vitamin D 
have been used in an attempt to strengthen the skeleton. Extensive recalcification of bone has been reported in a myeloma patient treated for 22 months with $90 \mathrm{mg}$ of sodium fluoride and $3.5 \mathrm{~g}$ calcium lactate daily (Cohen \& Gardner, 1964). However, a prospective clinical trial of the effect of sodium fluoride alone on the clinical course of myeloma failed to demonstrated any beneficial effect (Harley et al., 1972). The administration of fluorides stimulates osteoblasts, but the new bone is poorly mineralized and osteomalacia, a fall in serum calcium, and secondary hyperparathyroidism occur (Jowsey et al., 1968). The addition of calcium and vitamin $D$ prevents the appearance of poorly-mineralized bone in rats. Myeloma patients have been randomized to receive sodium fluoride ( $50 \mathrm{mg}$ twice daily), or a placebo, in addition to melphalan and prednisone (Kyle et al., 1975). After one year of treatment, microradiographic and video-densitometry studies of bone biopsies showed significant increases in bone formation and bone mass in the fluoride-calcium group. These changes could not be detected by technetium bone scans or roentgenographic films. The addition of 50,000 units of vitamin $\mathrm{D}$ twice weekly reduced the incidence of hypocalcaemia (Kyle \& Jowsey, 1980). The treatment was well tolerated. Nausea was experienced infrequently and was controlled by temporarily reducing the sodium fluoride to $50 \mathrm{mg}$ daily.

Based on these findings, the Mayo Clinic investigators recommend that myeloma patients who are responding to chemotherapy should be treated with sodium fluoride and calcium carbonate. The addition of 50,000 units of vitamin D twice weekly may be helpful, but further experience will be required to establish this. It should be noted that serum creatinine, calcium and fluoride levels must be determined at 6 to 12 week intervals to monitor this therapy. The development of renal insufficiency, or release of fluoride from bone during progression of the myelomatous bone lesions, can lead to elevated blood fluoride levels and toxicity. For this reason serum creatinine, calcium and fluoride levels must be monitored frequently during treatment, and continued even after sodium fluoride is discontinued.

Despite the encouraging results of these pilot studies by the Mayo Clinic group, no large scale evaluation of the clinical benefits of long-term treatment with sodium fluoride, calcium and vitamin $\mathrm{D}$ have been reported.

The use of diphosphonates in maintaining the bony skeleton of myeloma patients has also been considered. Diphosphonates are synthetic analogues of pyrophosphate, an endogenous inhibitor of hydroxyapatite crystal formation. In vitro, diphosphonates can modify the crystal growth of calcium hydroxyapatite by chemisorption onto the crystal surface. Some studies have suggested that, after absorption to the surface of hydroxyapatite. diphosphonates are ingested by osteoclasts engaged in bone resorption. inhibiting various metabolic functions within these cells (Russell \& Fleisch, 1975).

\section{The role of maintenance therapy}

Myeloma patients who respond to initial therapy achieve a remission after a one to two logarithm reduction in the myeloma cell mass. Attempts to reduce the tumour mass further with continued, or more aggressive therapy usually fail. During this therapeutic plateau the myeloma cell mass is often stable for months to years.

In an innovative study, the SWOG tested the value of continuing maintenance therapy. Patients who achieved a satisfactory response to induction chemotherapy with melphalan, procarbazine and prednisone, or melphalan, procarbazine, vincristine and prednisone, and were treated for at least 12 months, were randomized to no maintenance therapy, or maintenance treatment with either carmustine (BCNU) and prednisone or melphalan and prednisone. Patients who relapsed on no maintenance therapy were treated again with melphalan and prednisone and 16 of $20(80 \%)$ achieved a second remission. None of the nine patients treated with melphalan and prednisone after relapsing from $\mathrm{BCNU} /$ prednisone maintenance therapy, achieved a second response. No significant difference was found in the total duration of remissions, or the survival of patients who received maintenance therapy and those who did not (Southwest Oncology Group Study, 1975; Alexanian et al., 1978).

In a second study, the value of BCG immunization in prolonging remission durations and survival of myeloma patients was tested (Alexanian et al., 1978). Remission induction therapy was with CAP, VCAP, VMCP or VBAP (See footnote to Table II for the drugs represented by these letters) for six months. Responders were continued on consolidation treatment with intermittent courses of VMCP and BCG for 12 months. Of the 105 patients started on VMCP. BCG, 30 relapsed or died during the 12 months of consolidation therapy. The median duration of unmaintained remission for the 69 evaluable patients was only 9 months. When VMCP was restarted on 20 relapsing patients at the M.D. Anderson Hospital, 10 achieved a $50 \%$ decrease in myeloma cell mass. No advantage could be demonstrated for the more aggressive remission-induction schedules, or for consolidation with VMCP-BCG.

The National Cancer Institute of Canada Clinical Trials group (NCI-C) has also tested the value of maintenance therapy (Belch et al., 1984). Myeloma patients were treated initially with intermittent courses 
of melphalan and prednisone. Those who achieved a stable objective response by the Chronic LeukemiaMyeloma Task Force (1968) criteria ( $>50 \%$ reduction in M-protein), which remained stable for at least four months, were randomized to continue intermittent courses of melphalan and prednisone, or to discontinue this treatment until disease progression occurred. Of those who progressed on no maintenance therapy, $50 \%$ achieved a second remission following treatment with melphalan and prednisone. In this study, the duration of the first remission was significantly longer in the group receiving maintenance therapy, but when the duration of subsequent remissions was added to that of the first in the no maintenance arm, the total remission duration of the two groups was similar. No significant difference was observed in the overall survival of the two groups. To date, two patients receiving maintenance therapy, and one on the no maintenance group have developed acute leukaemia.

Thus, in three different clinical trials, continuing treatment after satisfactory remission induction has not been shown to prolong either the total duration of remissions or overall survival. Since melphalan may play a role in the induction of acute leukaemia in myeloma patients, it has been my practice to discontinue melphalan therapy after a stable remission has been achieved, and to restart it again when signs of disease progression occur.

\section{Resistant myeloma}

There are at least three groups of patients with resistant myeloma. The first are patients who fail to respond to induction chemotherapy. These patients are thought to have primary, as opposed to acquired resistance to chemotherapeutic agents. The second are those who respond initially and then relapse despite continued treatment. These patients have acquired resistance to an agent to which their myeloma cells were initially sensitive, and are referred to as relapsing hereafter. A third group are the myeloma patients who enter the acute phase of the disease with pancytopenia. The marrow failure appears to be caused by disease progression, rather than treatment, because the marrow is usually hypercellular (Bergsagel and Pruzanski, 1975). These patients have progressive, aggressive myeloma, and may form extramedullary plasmacytomas. The marrow failure appears as part of the course of the disease, and may be a prelude to acute leukaemia, as occurs during the accelerated phase of chronic myelogenous leukaemia.

Patients with primary resistance, who do not respond to their initial therapy, have a poor prognosis, for only $10 \%$ respond to alternate therapy with conventional doses of prednisone and agents such as adriamycin, vincristine, carmustine (BCNU), CCNU and cyclophosphamide (reviewed by Bergsagel and Rider, 1985).

Patients who respond to primary therapy, and then relapse, have a better chance of responding to alter- $\stackrel{0}{?}$ nate therapy. As noted above, from 40 to $80 \%$ of ? patients who relapse on no maintenance therapy will achieve a second response to retreatment. Those who relapse on maintenance treatment are more resistant, for only about $25 \%$ of these patients will respond to alternate therapy (Bergsagel \& Rider, 1985).

Little is known about the response of patients, who have entered the acute phase of myeloma, to alternate therapy. These patients have marrow failure (i.e. pancytopenia with a cellular marrow) and rapidly progressing myeloma. Their myeloma cells may still be sensitive to the chemotherapeutic agents employed. However, regrowth of the myeloma cells often occurs more rapidly than the recovery of marrow function, and a stable remission with improved marrow function is rarely achieved. These patients are often grouped with other types of myeloma patients with advanced, resistant disease, and their response to treatment has not been studied separately.

Prednisone has been known to be active in the treatment of myeloma patients for many years (Salmon et al., 1967), and recently high dose prednisone alone $\left(60 \mathrm{mg} / \mathrm{m}^{2} / \mathrm{d}\right.$ for 5 days, repeated every 8 th dai has produced a greater than $50 \%$ reduction in the myeloma cell mass in 5 of 16 myeloma patients refractory to alkylating agents (Alexanian et al., 1983). Prednisone is especially useful in the treatment of patients who develop pancytopenia during the acute phase of the disease. In some patients the haemoglobin, leukocyte and platelet counts will rise after high-dose prednisone is started, and this may be associated with a fall in the serum and urinary $M$ protein. The increased corticosteroid dose (dexamethasone $40 \mathrm{mg} / \mathrm{d}$ for four days beginning on days 1,9 and 17 of each cycle), combined with four day infusions of vincristine and doxorubicin (VAD), probably contributes greatly to the success of this regimen in inducing responses in 6 of 14 previously unresponsive, and 11 of 15 relapsing patients (Barlogie et al., 1984).

\section{Acute leukaemia}

Myeloma patients have a markedly increased risk of $\tilde{N}$ developing acute leukaemia. In a series of 364 Can- N adian patients treated with alkylating agents, the N actuarial risk of developing acute leukaemia was $17 \%$ at 50 months. The incidence of acute leukaemia in this group of patients was 230 times greater than the expected incidence for all forms of acute leukaemia in Canada (Bergsagel et al., 1979).

The two major hypotheses to explain the high 
incidence of acute leukaemia in myeloma patients are: (a) treatment with alkylating agents and irradiation may induce gene mutations, or activate latent neoplastic viruses, which induce leukaemia; and (b) acute leukaemia is part of the natural history of plasma cell neoplasms, as it is with other clonal haemopathies such as chronic granulocytic leukaemia, polycythaemia vera and myelofibrosis.

The evidence in favour of these hypotheses has been reviewed elsewhere (Bergsagel, 1982). The suggestion that the acute leukaemia is caused by treatment is not very satisfactory. If this hypothesis were true one would not expect an increased incidence of acute leukaemia in untreated patients. However, by 1981 at least 41 instances of acute leukaemia in untreated patients had been reported. Furthermore, if gene mutations, or latent virus activation were to result from treatment, one would expect to find an increased incidence of second malignancies other than acute leukaemia in myeloma patients, and this has not been observed.

\section{References}

ABRAMSON, N., LURIE, P., MIETLOWSKI, W.L., SCHILLING, A., BENNETT, J.M. \& HORTON, J. (1982). Phase III study of intermittent carmustine (BCNU) cyclophosphamide and prednisone versus melphalan and prednisone in multiple myeloma. Cancer Treatment Reports, 66, 1273.

ALEXANIAN, R. \& DREICER, R. (1984). Chemotherapy for multiple myeloma. Cancer, 53, 583.

ALEXANIAN, R., GEHAN, E., BONNET, J., HAUT, A., HEWLETT, J., LANE, M., MCKELVEY, E.M., MIGLIORE, P.H., STUCKEY, W.J. \& WILSON, H.E. (1972). Combination chemotherapy for multiple myeloma. Cancer, 30, 382.

ALEXANIAN, R., GEHAN, E., HAUT, A., SAIKI, J. \& WEICK, J. (1978). Unmaintained remissions in multiple myeloma. Blood, 51, 1005.

ALEXANIAN, R., YAP, B.S. \& BODEY, G.P. (1983). Prednisone pulse therapy for refractory myeloma. Blood, 62, 572.

BARLOGIE, B., SMITH, L. \& ALEXANIAN, R. (1984). Effective treatment of advanced multiple myeloma refractory to alkylating agents. New England Journal of Medicine, 310, 1353.

BELCH, A., WHITE, D., BERGSAGEL, D., WILSON, K. \& SHELLEY, W. (1984). The role of maintenance chemotherapy for multiple myeloma. Proceedings of the American Society of Clinical Oncology, 3, 268 (abstract c-1050).

BERGSAGEL, D.E. (1982). Is multidrug chemotherapy necessary for multiple myeloma? In: Controversies in Oncology, Wiernik, P.H. (Ed), p. 81, John Wiley \& Sons: New York.

BERGSAGEL, D.E. (1983) Editorial: Progress in the treatment of plasma cell myeloma? Journal of Clinical Oncology, 1, 510.

BERGSAGEL, D.E. (1984). Letter to the Editor. Journal of Clinical Oncology, 2, 247.

BERGSAGEL, D.E., BAILEY, A.J., LANGLEY, G.R., MACDONALD, R.N., WHITE, D.R. \& MILLER, A.B. (1979). The chemotherapy of plasma cell myeloma and the incidence of
The hypothesis that acute leukaemia is part of the natural history of plasma cell neoplasms appears to be more plausible than the first hypothesis, but will be difficult to establish until the mechanism responsible for this phenomenon is discovered.

The true explanation for the increased incidence of acute leukaemia may be a mixture of the two hypotheses, e.g., myeloma patients may have an increased tendency to develop acute leukaemia, and this may be aggravated by treatment with some alkylating agents. In the first myelomatosis trial conducted by the MRC, 258 patients were randomized to treatment with either melphalan or cyclophosphamide. This large group of patients have now been followed for a minimum of 12 years, and 6 patients, all treated with continuous melphalan have developed acute myeloid leukaemia. The failure to detect acute leukaemia in the patients treated with cyclophosphamide is remarkable, and suggests that the type of alkylating agent used for treatment influences the risk of developing acute leukaemia (Buckman et al., 1982).

acute leukemia. New England Journal of Medicine, 301, 743.

BERGSAGEL, D.E. \& PRUZANSKI, W. (1975). Treatment of plasma cell myeloma with cytotoxic agents. Archives of Internal Medicine, 135, 172.

BERGSAGEL, D.E. \& RIDER, W.D. (1985). Plasma cell neoplasms. In Cancer: Principles and Practice of Oncology, DeVita, V.T., Hellman, S. \& Rosenberg, S. (Eds), 2nd Edition. Lippincot: Philadelphia and Toronto (in press).

BUCKMAN, R., CUZICK, J. \& GALTON, D.A.G. (1982). Longterm survival in myelomatosis. A report to the MRC working party on leukaemia in adults. British Journal of Haematology, 52, 589.

CASE, D.C. JR, LEE, B.J., III \& CLARKSON, B.D. (1977). Improved survival times in multiple myeloma treated with melphalan, prednisone, cyclophosphamide, vincristine and BCNU: M-2 protocol. American Journal of Medicine, $63,897$.

CAVAGNARO, F., LIEN, J.M., PAVLOVSKY, S., BECHERINI, J.O., PILEGGI, J.E., MICHEO, E.Q., JAIT, C., MUSSO, A., SUAREZ, A. \& PIZZOLATO, M. (1980). Comparison of two combination chemotherapy regimens for multiple myeloma: methyl-CCNU, cyclophosphamide and prednisone versus melphalan and prednisone. Cancer Treatment Reports, 64, 73.

CHRONIC LEUKEMIA-MYELOMA TASK FORCE, NATIONAL CANCER INSTITUTE (1968). Proposed guidelines for protocol studies. II Plasma cell myeloma. Cancer Chemotherapy Reports, 1, 17.

COHEN, P. \& GARDNER, F.H. (1964). Induction of subacute skeletal fluorosis in a case of multiple myeloma. New England Journal of Medicine, 271, 1129.

COOPER, M.R., MCINTYRE, O.R, ANDERSON, K., KYLE, R.A., SILVERFARB, P. \& FREI, E., III. (1983). The effectiveness of single versus multiple alkylating agents with and 
without adriamycin in the primary treatment of multiple myeloma. Blood 62 (Suppl. 10), 211 a, (abstract, 748).

HARLEY, J.P., PAJAK, T.F., MCINTYRE. O.R., KOCHWA, S., COOPER, M.R., COLEMAN. M. \& CUTTNER, J. (1979). Improved survival of increased risk myeloma patients on combined triple-alkylating agent therapy: A study of the CALGB. Blood, 54, 13

HARLEY, J.B., SCHILLING, A. \& GLIDWELL, O. (1972). Ineffectiveness of fluoride therapy in multiple myeloma. New England Journal of Medicine, 286, 1283.

JOWSEY, J., SCHENK, R.K. \& REUTTER, F.W. (1968). Some results of the effect of fluoride on bone tissue in osteoporosis. Journal of Clinical Endocrinology and Metabolism, 28, 869.

KYLE, R.A. \& JOWSEY, J. (1980). Effect of sodium fluoride, calcium carbonate and vitamin $D$ on the skeleton in multiple myeloma. Cancer, 45, 1669.

KYI.E, R.A., JOWSEY, J., KELLY, P.J. \& TAVES. D.R. (1975). Multiple myeloma bone disease. The comparative effect of sodium fluoride and calcium carbonate or placebo. New England Journal of Medicine, 293, 1334.

LEE, B.J. (1984). Letter to the Editor. Journal of Clinical Oncology, 2, 245.

LEE, B.J., LAKE-LEWIN, D. \& MEYERS. J.E. (1982). Intensive treatment of multiple myeloma. In: Controversies in Oncology, Wiernik, P.H. (Ed), p. 61, John Wiley \& Sons: New York.

LIVINGSTON, K.E. \& PERRIN, R.G. (1978). The neurosurgical management of spinal metastases causing cord and cauda equina compression. Journal of Neurosurgery, 49, 839.

OKEN. M.M., TSIATIS, A., ABRAMSON, N. \& GLICK, J. (1984). Comparison of standard (MP) with intensive
(VBMCP) therapy for the treatment of multiple myeloma (MM). Proceedings of the American Society of Clinical Oncology, 3, 270 (abstract C-1055).

OSGOOD, E.E. (1960). The survival time of patients with plasmacytic myeloma. Cancer Chemotherapy Reports, 9, 1 . OSSERMAN, E.F., DIRE, L.B., DiRE, J., SHERMAN, W.H. HERSMAN, J.A. \& STOR B, R. (1982). Identical twin marrow transplantation in multiple myeloma. Acta Haematologica, 68, 215.

PAVLOVSKY, S., SASLAVSKY, J., TEZANOS PINTO, M., PALMER, L., CURUCHET, M., LEIN, J.M., GARAY, G. DRAGOSKY, M., QUIROGA-MICHEO, E., HUBERMAN, A \& PIZZOLATTO, M. (1984). Randomized trial of melphalan, prednisone versus melphalan, prednisone, cyclophosphamide, MeCCNU and vincristine in untreated multiple myeloma. Journal of Clinical Oncology (in press).

RUSSELL, R.G.G. \& FLEISCH, H. (1975). Pyrophosphate and diphosphonates in skeletal metabolism: Physiological, clinical and therapeutic aspects. Clinical Orthopedics, 108, 241.

SALMON, S.E., HAUT, A., BONNET, J., AMARE. M., WEICK, J.K., DURIE, B.G.M. \& DIXON, D.O. (1983). Alternating combination chemotherapy and levamisole improves survival in multiple myeloma: A Southwest Oncology Group Study. Journal of Clinical Oncology, 1, 453.

SALMON, S.E., SHADDUCK, R.K. \& SCHILLING, A. (1967). Intermittent high-dose prednisone (NSC-10023) therapy for multiple myeloma. Cancer Chemotherapy Reports, 51, 179.

SOUTHWEST ONCOLOGY GROUP STUDY (1975). Remission maintenance therapy for multiple myeloma. Archives of Internal Medicine, 135, 147. 